\title{
A potential treatment regimen in SARS-CoV-2 patients
}

\author{
Nezam Hadibarhaghtalab ${ }^{1}$, Maryam Hadibarhaghtalab ${ }^{1}$, Parisa Hosseinpour ${ }^{1}$, and Vahid \\ Seifi $^{1}$
}

${ }^{1}$ Affiliation not available

November 3, 2020

\begin{abstract}
In December 2019, the COVID-19 outbreak began in Wuhan, China, and soon announced as a pandemic in March 2020 and Iran was no exception. Since COVID-19 is a newly emerging disease, no definite treatment exists and therapy is based upon supportive care. Many treatment regimens have been proposed and some of which have shown promising results that may be considered as the treatment of COVID-19 in the near future if confirmed by further studies. As there is no gold standard for the treatment of COVID-19 and many physicians in different countries prescribe a combination of drugs, we prescribed a combination of drugs. based on the above evidence to patients referring to our clinic. We monitored and analyzed patients with mild to moderate symptoms with the inclusion criteria of either confirmed COVID-19 cases by RT-PCR or had close contact with confirmed cases having symptoms of headache, sore throat, cough, diarrhea, unjustifiable symptoms in favor of vasculitis, and any cutaneous manifestations which last for more than 5 days. A total of thirty-three patients were included and then visited daily with their vital parameters being recorded directly. All thirty-three patients recovered from the disease with no complication after receiving the treatment and in follow up visits. Although a definite treatment for SARS-CoV-2 still remains a matter of debate, this treatment regimen showed effective treatment in patients with mild to moderate symptoms. Undoubtedly, further researches and papers are needed to be done to prove the effectiveness of this treatment regimen.
\end{abstract}

\section{Hosted file}

Title page.pdf available at https://authorea.com/users/372516/articles/490521-a-potentialtreatment-regimen-in-sars-cov-2-patients

\section{Hosted file}

letter to the editor COVID-19 treatment regimen R1 copy.pdf available at https://authorea. com/users/372516/articles/490521-a-potential-treatment-regimen-in-sars-cov-2-patients

\section{Hosted file}

Table 1.pdf available at https://authorea.com/users/372516/articles/490521-a-potentialtreatment-regimen-in-sars-cov-2-patients 